\section{Case Report}

\section{Corresponding Author}

Kartik Manoj Multani

(iD https://orcid.org/0000-0001-5038-3917

Department of Neurosurgery, Yashoda

Superspeciality Hospital, Secunderabad (500003), India

Email: Kartik.multani@gmail.com

Received: June 1, 2020

Revised: July 17, 2020

Accepted: September 12, 2020

\title{
Anterior Spinal Cord Fissuring: A Predictor of Spontaneous Resolution of Syrinx?
}

\author{
Kartik Manoj Multani ${ }^{1}$, Boyina Jagadeshwar Rajesh ${ }^{1}$, Krishna Kumar ${ }^{1}$, \\ Anjani Kumar ${ }^{2}$ \\ ${ }^{1}$ Department of Neurosurgery, Yashoda Hospital, Hyderabad, India \\ ${ }^{2}$ Department of Radiodiagnosis, Yashoda Hospital, Hyderabad, India
}

Syringomyelia is a disorder of the spinal cord usually seen in association with a variety of craniovertebral junction anomalies (e.g., Chiari malformations, basilar invagination/impression, atlantoaxial instability, etc.). Its natural history is not very clearly understood and a majority of patients present with a slowly progressive neurological deficit followed by sudden rapid deterioration. At present, there is a general consensus to offer surgical decompression in all patients diagnosed with Chiari I malformation with syrinx irrespective of their symptoms in order to prevent delayed neurological worsening. Few authors have reported spontaneous resolution of syrinx with persistent tonsillar herniation without operative treatment. We report one such patient and propose anterior spinal cord fissuring as a plausible cause of spontaneous syrinx drainage. We also propose conservative management for patients with an anterior spinal cord fissure seen in index scans instead of early decompression of Chiari malformation.

Keywords: Spontaneous resolution of syrinx, Syringomyelia, Chiari malformation, Conservative management of Chiari with syrinx

\begin{abstract}
Copyright $\odot 2021$ by the Korean Spinal
Neurosurgery Society

This is an Open Access article distributed under the terms of the Creative Commons Attribution Non-Commercial License (https://creativecommons.org/licenses/by-nc/4.0/) which permits unrestricted non-commercial use, distribution, and reproduction in any medium, provided the original work is properly cited.
\end{abstract}

\section{INTRODUCTION}

Syringomyelia is a multifactorial affliction of the spinal cord that results in a tubular cavitation in the center of the cord. ${ }^{1,2}$ The basic pathogenesis lies in abnormal flow dynamics of cerebrospinal fluid (CSF). Usually, this entity is associated with craniovertebral junction anomalies such as atlantoaxial dislocation, basilar invagination, occipital encephalocele, and Chiari I malformation. ${ }^{3}$ The natural history of syringomyelia is not clearly understood and varies across patients. Most patients show a period of stability followed by slow progression over months to years, with an early rapid deterioration that gradually slows down. ${ }^{4}$ However, some patients have reported spontaneous improvement in symptoms and shown resolution of syrinx on magnetic resonance imaging (MRI). So far, only a few reports have documented spontaneous resolution of syrinx with persistent tonsillar herniation in Chiari 1 malformation, and in this report, we suggest spinal cord fissuring as a plausible cause of this outcome.

\section{CASE REPORT}

A 21-year-old woman with a history of birth asphyxia had an episode of generalized tonic-clonic seizure during sleep at the age of 12 years. She was evaluated with noncontrast computed tomography of the brain in 2010, which showed areas of hypodensity in the left temporal lobe, which were suggestive of ischemic damage, and the patient was managed conservatively with antiepileptics. In 2011, the patient had similar episode of seizures for which she underwent brain MRI, which showed gliosis in the left temporal lobe and bilateral occipital poles along with an incidental finding of tonsillar herniation with no evidence of syrinx, and a diagnosis of seizure disorder with Chiari I malformation was made (Fig. 1). The patient had similar epi- 

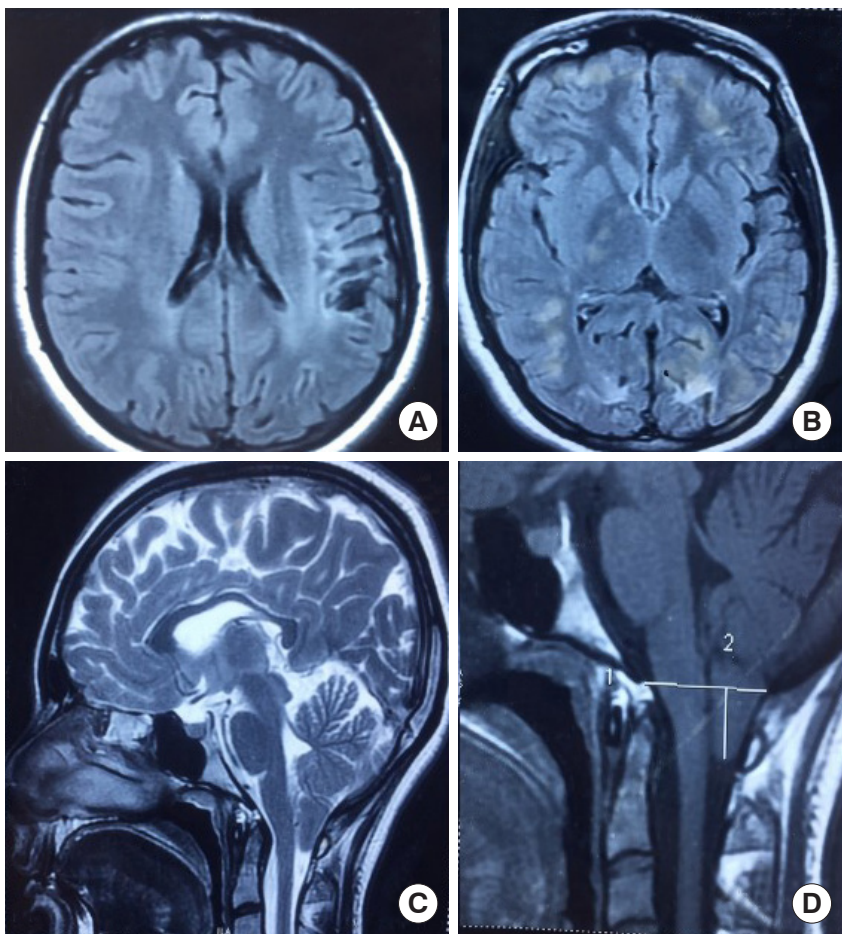

Fig. 1. (A) Brain magnetic resonance imaging T2-weightedfluid-attenuated inversion recovery (T2 FLAIR) showing an area of gliosis in the left temporal lobe. (B) T2 FLAIR showing an ischemic insult in the bilateral occipital regions. (C, D) Sagittal T2- and T1-weighted images demonstrating an incidental finding of tonsillar herniation without syrinx. sodes infrequently for 3 consecutive years and had multiple changes in the antiepileptic medication regimen under the care of a neurologist, after which she was seizure-free for 1 year.

In 2017, she had another episode of generalized tonic-clonic seizure and she was referred to the neurosurgery outpatient department (OPD). MRI showed similar cranial findings to those seen in the 2011 scan, with cervical cord syrinx at the C2 and C3 levels (Fig. 2). The patient reported no high cervical cord or posterior fossa symptoms. Considering the presence of a Chiari I malformation with a large syrinx, the patient was advised to undergo posterior fossa decompression with duraplasty, but the patient was not willing to do so and was lost to follow-up.

The patient returned to our OPD after 1 year (in 2018) and was willing to undergo surgery. The patient had been asymptomatic for syrinx/Chiari malformation since her index visit. A cervical spine MRI was ordered according to the routine preoperative imaging protocol. To our surprise, MRI showed persistent tonsillar herniation, as seen in 2017, but no syrinx in the cervical cord (Fig. 3). We retrospectively reviewed all the radiological investigations and found a fissure in the substance of the spinal cord anterior to the syrinx that connected it to the subarachnoid space (SAS) in the 2017 MRI study (Fig. 4). During the course of her treatment, she remained asymptomatic for cervical disease.
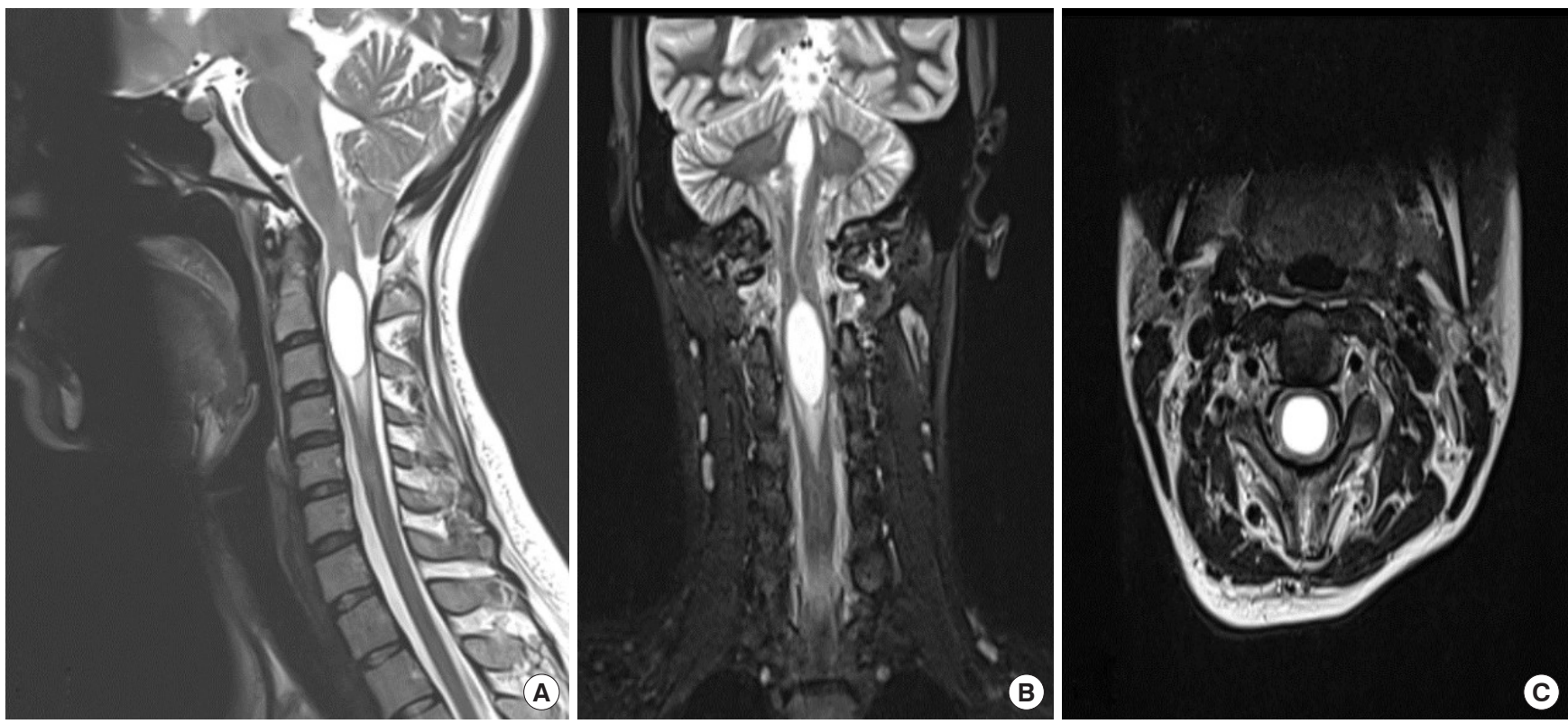

Fig. 2. T2-weighted image magnetic resonance imaging showing a syrinx behind C2 and C3 with tonsillar herniation through the foramen magnum. 

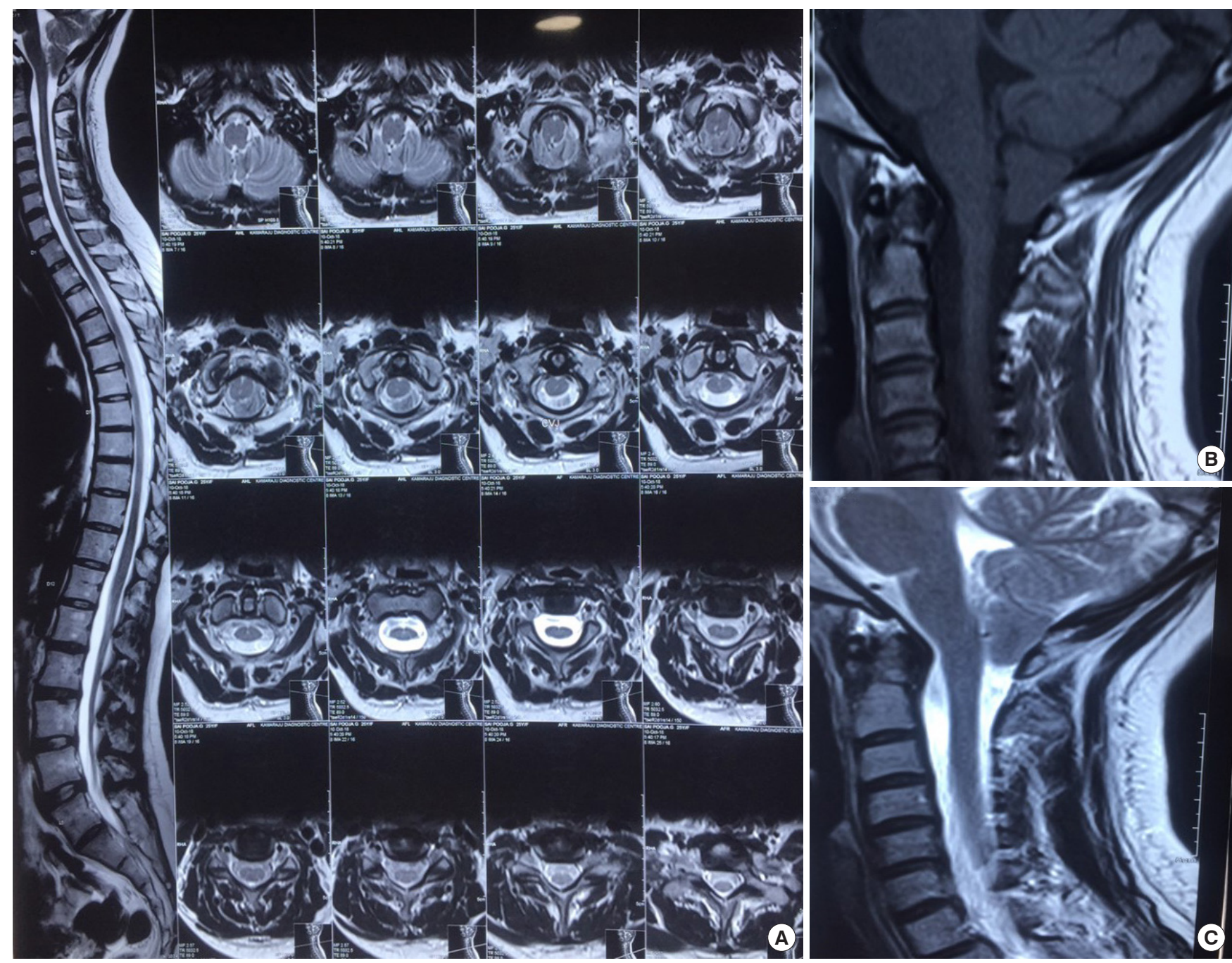

Fig. 3. Magnetic resonance imaging of the cervical spine showing persistent tonsillar herniation with no syrinx.
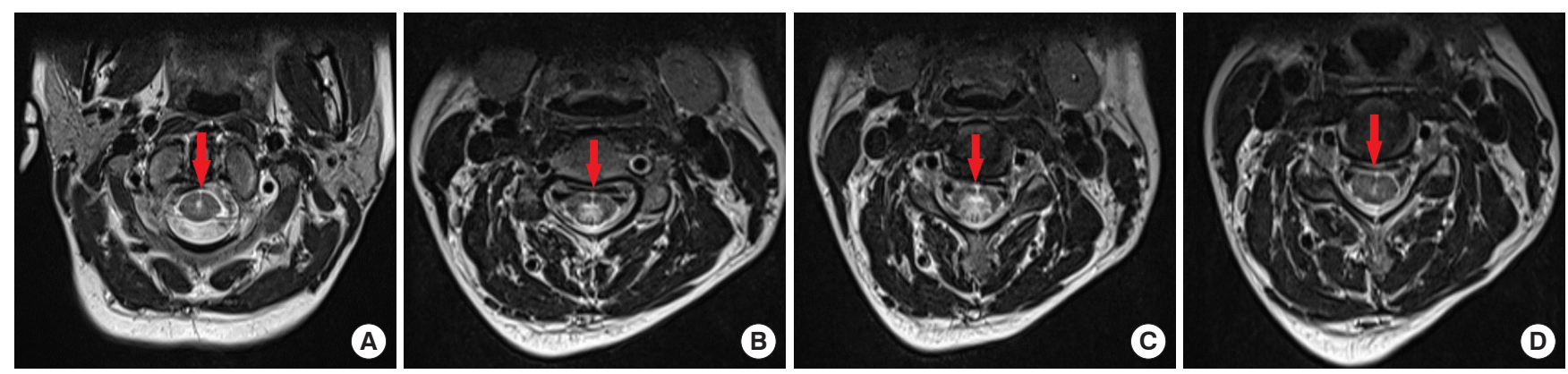

Fig. 4. Axial T2-weighted image showing a cord fissure connecting the syrinx to the subarachnoid space (red arrow).

\section{DISCUSSION}

Several theories have been proposed regarding the formation of syringomyelia. The most widely accepted "suck and slosh" theory was proposed by Williams, according to which the ton- sillar herniation in Chiari malformation acts as a 1-way ball valve obstructing the CSF flow, which results in pressure dissociation between the intracranial and spinal subarachnoid compartment whenever there is raised intracranial pressure. This leads to "sucking" of CSF from the intracranial space into the 


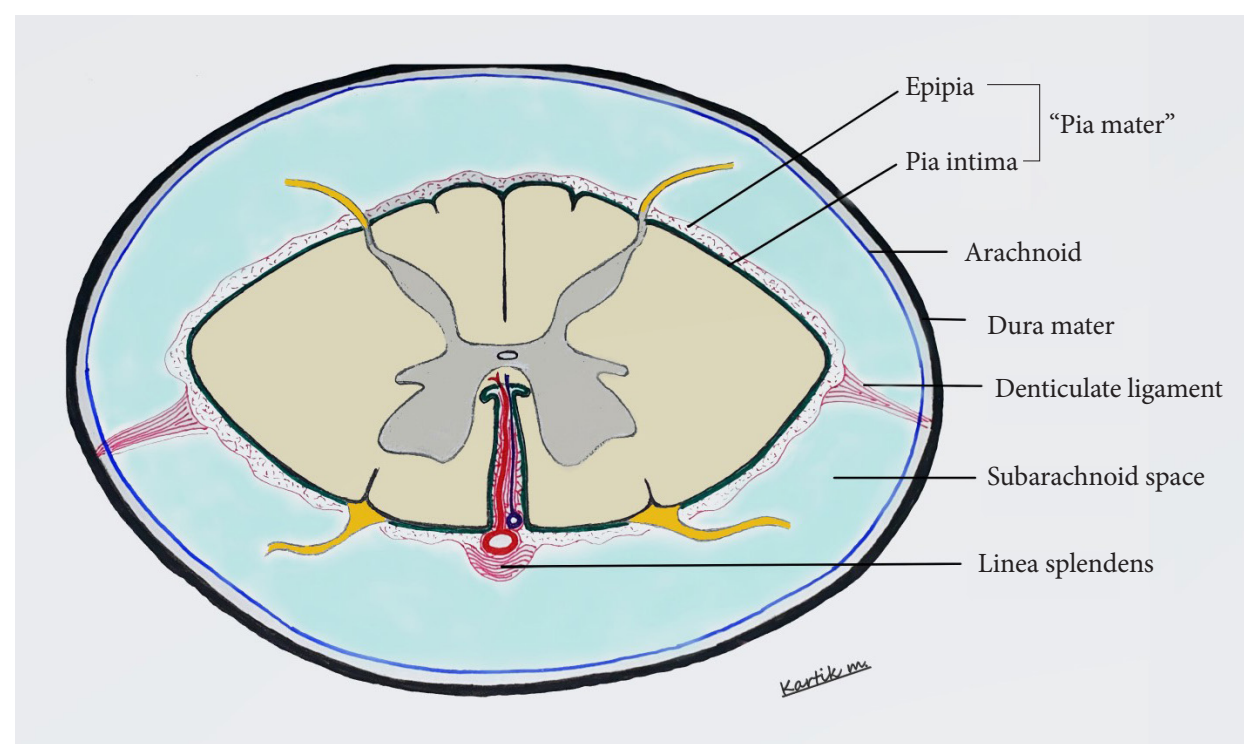

Fig. 5. Diagram illustrating the spinal pia mater with the inner reticular pia intima (green) and outer collagenous epipia (pink) and their relationship to the spinal cord.

central canal, thereby initiating the formation of a syrinx cavity in low-pressure areas of the cord. Then, through the "slosh" mechanism, the cavity keeps increasing in size craniocaudally due to intracavitary fluid movement secondary to pressure changes in the epidural venous system during Valsalva maneuvers (coughing, sneezing, straining, exercising). ${ }^{4,5}$

Key and Retzius in 1875 were the first to describe the leptomeningeal anatomy of the spine and their concept was later strengthened by Millen and Woollam's ${ }^{6}$ histopathologic study of the spinal pia mater. They divided the spinal pia mater into an inner, waterproof, thin reticular layer known as the "intima pia," which follows the contour of neural tissues and dips into sulcal spaces, where it joins with perivascular pia of vessels. External to this reticular layer is a semipermeable, mesh-like layer of collagenous tissue known as the "epipial layer." This layer thickens anteriorly to cover the anterior median fissure (linea splendens) and laterally to form the "denticulate ligament" (Fig. $5){ }^{6}$

The "slosh" mechanism may be a probable mechanism for forming a communication between the anterior median fissure and ventral spinal SAS by dissection through the anterior white matter fibers and rupture of the potentially weak waterproof intima pia at the footplate of the anterior median sulcus, which in our case may have led to egress of CSF from the syrinx to the anterior SAS through the semipermeable epipial layer, resulting in spontaneous resolution of syringomyelia.

To date, many reports have described possible theories for the spontaneous resolution of syrinx and Chiari malformation
Table 1. Studies describing spontaneous resolution of syrinx with persistent tonsillar herniation

\begin{tabular}{|c|c|c|c|}
\hline Study & $\begin{array}{l}\text { Age/ } \\
\text { sex }\end{array}$ & Interval & $\begin{array}{l}\text { Plausible theory for spontaneous } \\
\text { resolution }\end{array}$ \\
\hline $\begin{array}{l}\text { Jack et al. } \\
\text { (1991) }\end{array}$ & $30 / \mathrm{F}$ & 1.5 Years & $\begin{array}{l}\text { Dissection of syrinx into an atro- } \\
\text { phied hemicord driven by exer- } \\
\text { tion (Valsalva maneuver) }\end{array}$ \\
\hline $\begin{array}{l}\text { Santoro et al. }{ }^{8} \\
(1993)\end{array}$ & $\begin{array}{c}39 / \mathrm{M} \\
31 / \mathrm{F}\end{array}$ & $\begin{array}{l}3.1 \text { Years, } \\
<4 \text { years }\end{array}$ & $\begin{array}{l}\text { Spontaneous fissure connecting } \\
\text { syrinx from subarachnoid space }\end{array}$ \\
\hline $\begin{array}{l}\text { Sudo et al. }{ }^{11} \\
\text { (1998) }\end{array}$ & $11 / \mathrm{F}$ & 5.4 Years & $\begin{array}{l}\text { Improvement of flow around the } \\
\text { foramen magnum }\end{array}$ \\
\hline $\begin{array}{l}\text { Fukutake and } \\
\text { Hattori }^{12} \\
(1998)\end{array}$ & $40 / \mathrm{F}$ & 2 Months & $\begin{array}{l}\text { Resolution of reversible hydro- } \\
\text { myelia after cessation of breath- } \\
\text { holding activities in a profes- } \\
\text { sional swimmer }\end{array}$ \\
\hline $\begin{array}{l}\text { Itoyama et al. }^{13} \\
(2001)\end{array}$ & $54 / \mathrm{M}$ & 1.3 Years & - \\
\hline Present study & $21 / \mathrm{F}$ & 1 Year & $\begin{array}{l}\text { Spontaneous anterior spinal cord } \\
\text { fissuring draining the syrinx } \\
\text { into the subarachnoid space }\end{array}$ \\
\hline
\end{tabular}

simultaneously, but very few reports have described spontaneous reduction of syrinx with persistent tonsillar herniation ( $\mathrm{Ta}-$ ble 1).

Jack et al. ${ }^{7}$ (1991) were the first group to demonstrate complete resolution of syrinx with no change in tonsillar herniation confirmed by serial MRI. They proposed that the syrinx drained into the SAS from the site of hemicord atrophy seen on MRI. Santora et al. ${ }^{8}$ (1993) reported 2 cases with near-total disappearance of syrinx in 2 patients with Chiari malformation and 
validated the theory proposed by Jack et al. by demonstrating a channel between the syrinx and spinal SAS on MRI. Other proposed mechanisms include cessation of daily physical activity, rupture of arachnoid membranes, and recanalization of CSF pathways around the foramen magnum, ${ }^{9}$ as well as the proposal that a long seizure-free period in a patient with syrinx could reduce the intracranial pressure and in turn intraspinal pressure. ${ }^{10}$ In our case, there was no reduction in the patient's physical activity or seizure frequency and the syrinx spontaneously resolved with persistent tonsillar herniation. We demonstrated radiological confirmation of a spinal cord fissure connecting the syrinx to the SAS, thereby providing evidence corroborating the theory proposed by Jack et al. ${ }^{7}$ and Santoro et al. ${ }^{8}$

Spontaneous resolution of syrinx with persistent tonsillar herniation in patients with Chiari malformation is very rare. Fewer than 10 such cases have been reported in the literature. The role of abnormal CSF flow is very well established in development of syrinx, but due to the variable natural history of the disease, the correct pathogenesis and predictive factors for spontaneous resolution of syrinx have not been clearly established. This uncertainty challenges the present recommended surgical treatment of syrinx in all patients.

In our report, we propose that spinal cord fissure, which may be seen on T2-weighted MRI as a linear hyperintensity at the area of the anatomical anterior median fissure connecting the anterior SAS to the syrinx cavity, may be a predictive radiological sign for spontaneous resolution of syrinx. Therefore, we recommend conservative follow-up for such patients who are asymptomatic and not to consider surgery irrespective of the size of the syrinx. Further studies, including the documentation of flow across such fissures with a CSF flow study (cine-MRI), are needed to support this proposal. Moreover, the reduction of syrinx can result in an increased space at the craniospinal junction, which can promote progression of tonsillar herniation. Therefore, we recommend close, regular clinical and radiological follow-up for such patients to detect early signs of worsening tonsillar herniation even after the complete resolution of syrinx.

\section{CONFLICT OF INTEREST}

The authors have nothing to disclose.

\section{REFERENCES}

1. Vandertop WP. Syringomyelia. Neuropediatrics 2014;45:3-9.

2. Jain PK, Sreeharsha SV, Dugani S. Spontaneous resolution of syringomyelia in Chiari I malformation: a review of literature. Neurology India 2017;65:1187-9.

3. Weier K, Naegelin Y, Thoeni A, et al. Non-communicating syringomyelia: a feature of spinal cord involvement in multiple sclerosis. Brain 2008;131(Pt 7):1776-82.

4. Williams B. Pathogenesis of syringomyelia. Lancet 1972;2: 969-70.

5. Barkovich AJ, Sherman JL, Citrin CM, et al. MR of postoperative syringomyelia. AJNR Am J Neuroradiol 1987;8:31927.

6. Millen JW, Woollam DHM. On the nature of the pia mater. Brain 1961;84:514-20.

7. Jack CR Jr, Kokmen E, Onofrio BM. Spontaneous decompression of syringomyelia: magnetic resonance imaging findings. Case report. J Neurosurg 1991;74:283-6.

8. Santoro A, Delfini R, Innocenzi G, et al. Spontaneous drainage of syringomyelia. Report of two cases. J Neurosurg 1993; 79:132-4.

9. Klekamp J, Iaconetta G, Samii M. Spontaneous resolution of Chiari I malformation and syringomyelia: case report and review of the literature. Neurosurgery 2001;48:664-7.

10. Mazumder A, Das S, Krishnan P. Spontaneous resolution of Chiari malformation and associated syringomyelia. Neurology India 2016;64:1335-6.

11. Sudo K, Tashiro K, Miyasaka K. Features of spontaneous improvement in syringomyelia with low-situated cerebellar tonsils. Acta Neurol Belgica 1998;98:342-6.

12. Fukutake T, Hattori T. Reversible hydromyelia in a synchronised swimmer with recurrent thoracic girdle pains. J Neurol Neurosurg Psychiatry 1998;65:606.

13. Itoyama Y, Kitamura I, Ushio Y. Spontaneous resolution of cervical syringomyelia. A case report. No Shinkei Geka 2001; 29:321-4. Japaness. 